This manuscript has been authored by Fermi Research Alliance, LLC under Contract No. DE-AC02-07CH11359

with the U.S. Department of Energy, Office of Science,

Office of High Energy Physics.

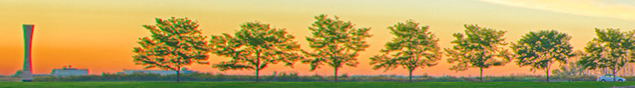

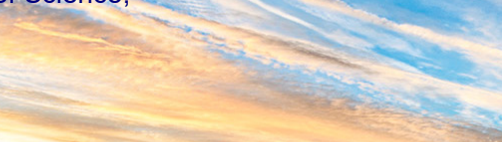

ana

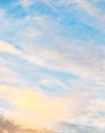

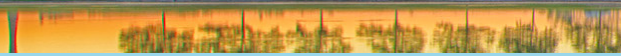

\title{
Alternate Crab Cavity Design
}

Andrei Lunin, Vyacheslav Yakovlev

October 27, 2021

\section{TRIUMF 2021 EIC Accelerator Partnership Workshop}

BROMITISTEN
NATIONAL LABORATORY

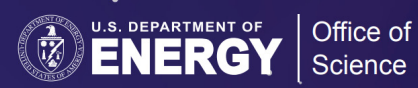

efferson Lab

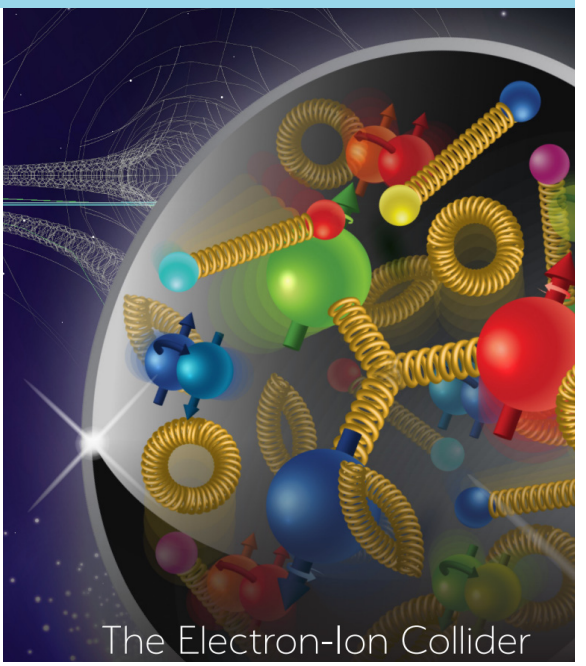

EIC2021, October 26-29, 2021 


\section{Outline}

- Concept of the HOM-free deflecting cavity

- QMiR (2.815 GHz) deflecting cavity for ANL/SPX project

- EM design

- Production and Testing

- QMiR (2.6 GHz) for ILC Crab Cavity

- HOM Analysis

- Mechanical Analysis (LFD and dF/dP)

- Frequency Tuner and Dressed Cavity Design

- QMiR (3 GHz and 3.25 GHz) for ELLETRA-II upgrade

- Conclusions 


\section{HOM-free Deflecting Cavity Concept}

\section{The key idea is based on the formation of TE "ghost" modes}

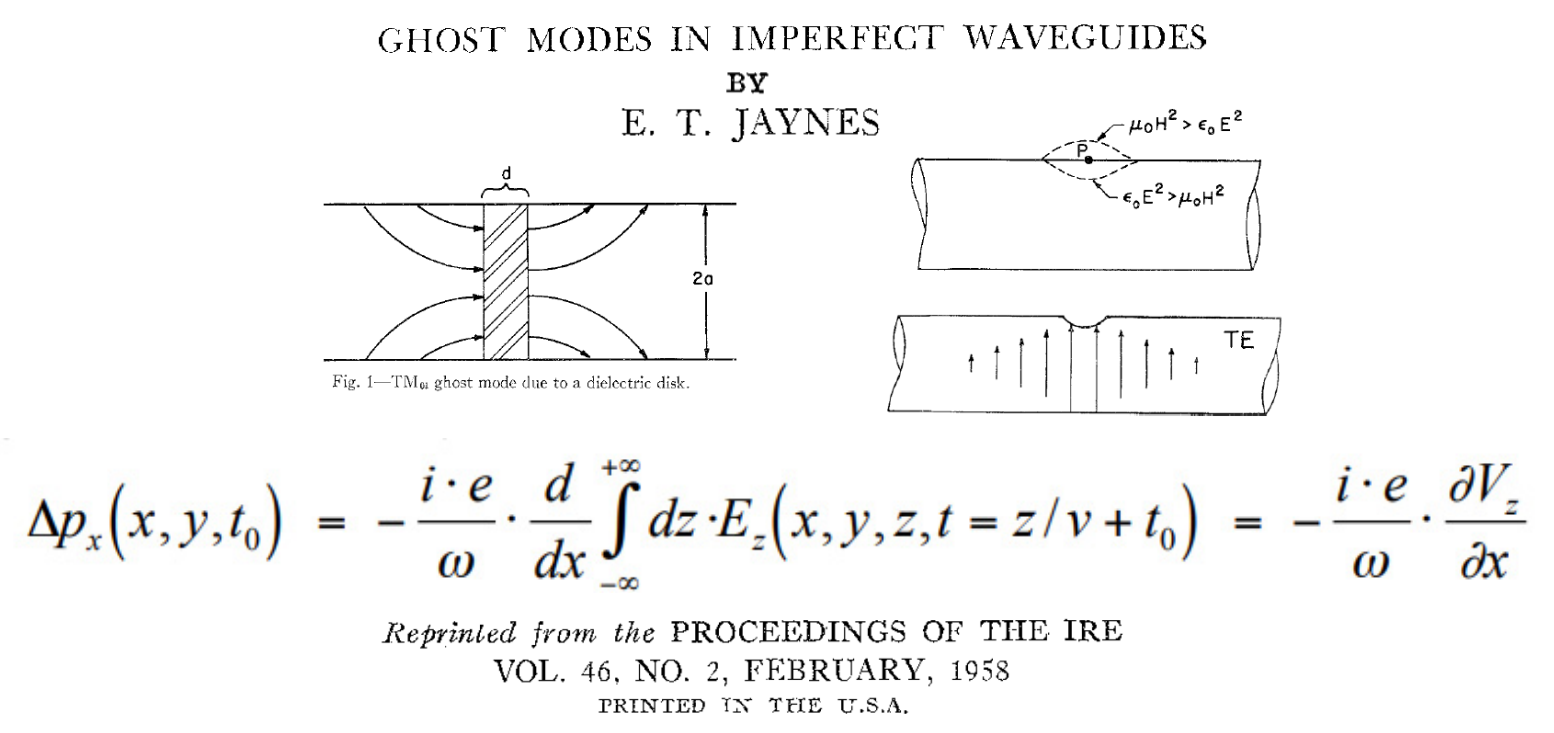

- Rediscovered in 1990s by G. Stupakov and S. Kurennoy [1]

- Further development of RFD at ODU (J. Delayen) [2]

- Transverse kick is produced by Quasi-TE modes which form transition zones with $\partial V_{z} / \partial x>0$

- no contradiction with the Panofsky/Wenzel theorem!

[1] PHYS. REV. VOL. 49-1, 1994

[2] PHYS. REV. SPECIAL TOPICS - ACCELERATORS AND BEAMS 16, 012004 (2013) 


\section{Compact HOM-free Deflecting Cavity QMIR}

\section{Quasi-Waveguide Multicell Deflecting Resonator [1]}

- Proposed as replacement of Mark-II deflecting cavity for APS/SPX project

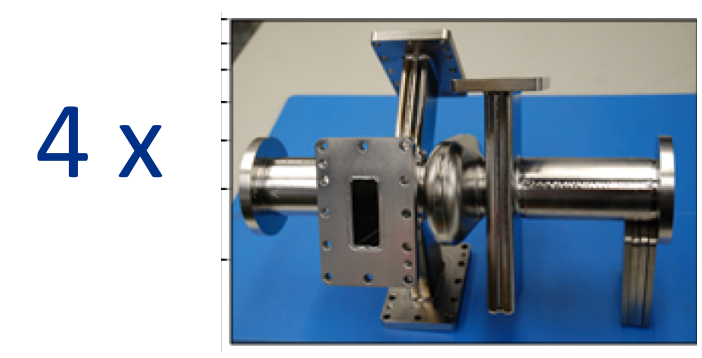

- Prototype built and tested at ANL in 2013 [2]

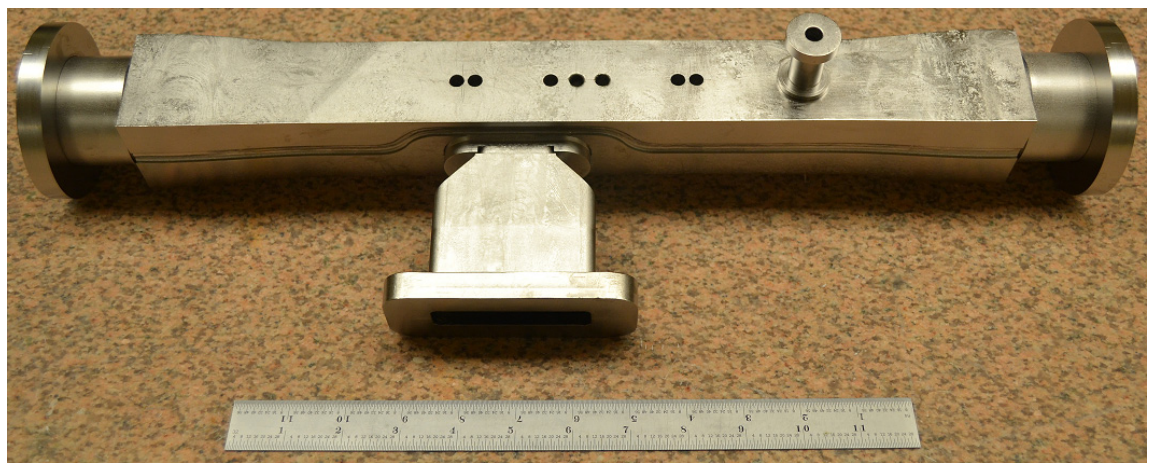

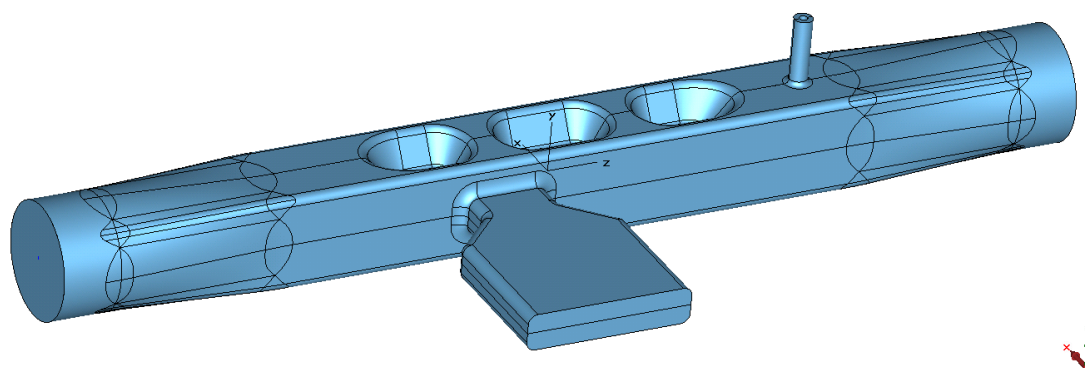

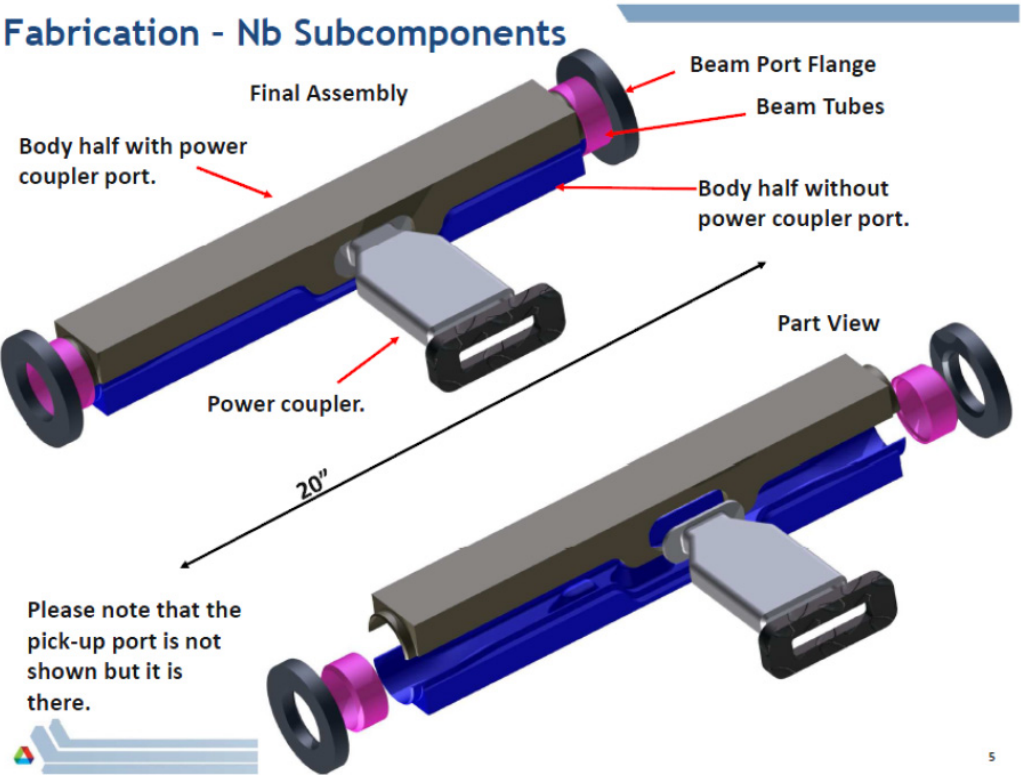

[1] A. Lunin, I. Gonin, M. Awida, T. Khabiboulline, V. Yakovlev, A. Zholents, Physics Procedia 79 ( 2015) $54-62$

[2] Zachary Conway on behalf of ANL PHY LINAC Development Group, 04/23/2013 


\section{R\&D on Deflecting Cavity for ANL/SPX}

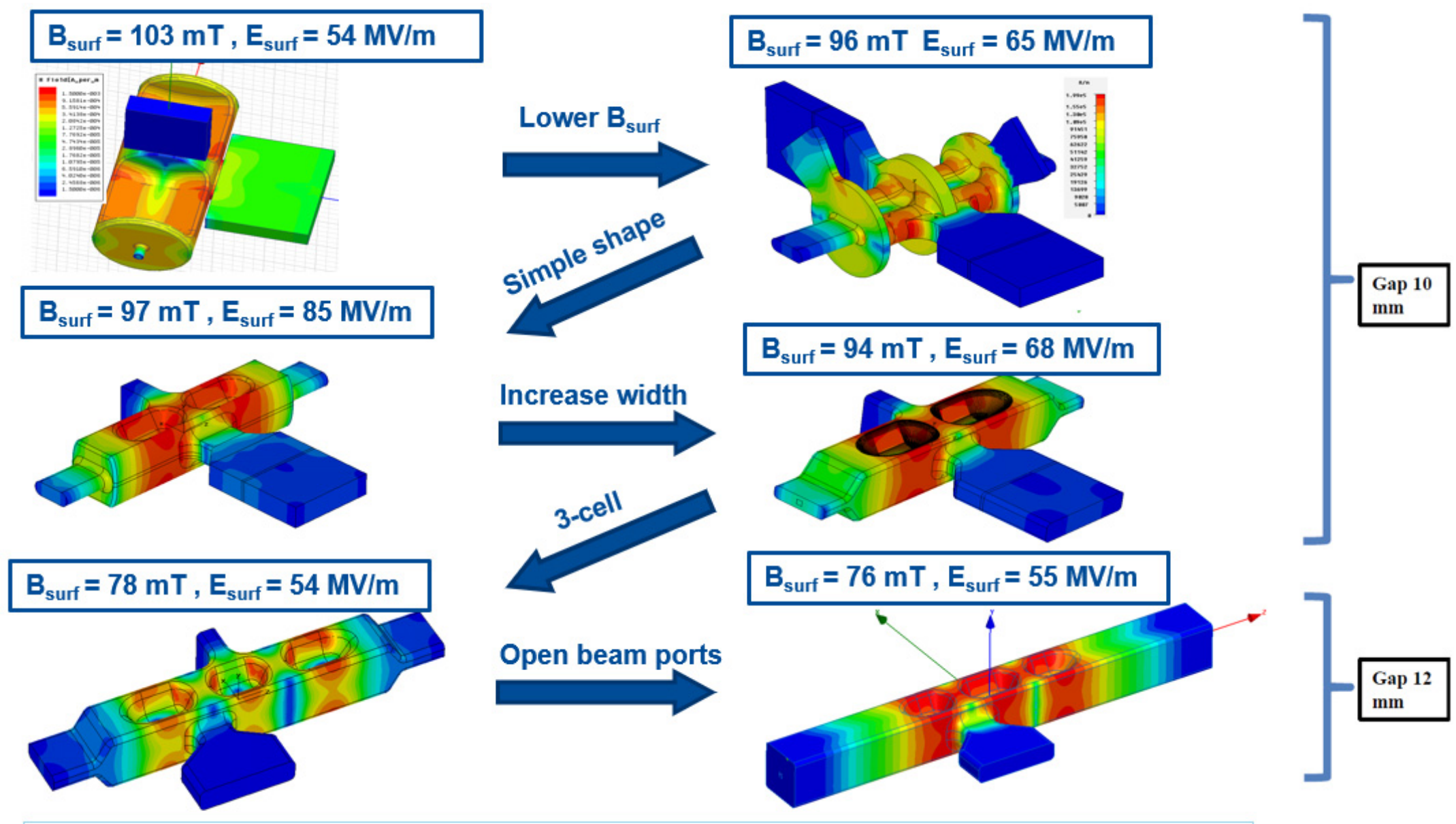

- Simple geometry

- Single WGs for HOM damping.

- Sparse spectrum of HOMs up to $5.1 \mathrm{GHz}$ and HOM free above $5.1 \mathrm{GHz}$ 


\section{R\&D on Deflecting Cavity for ANL/SPX}

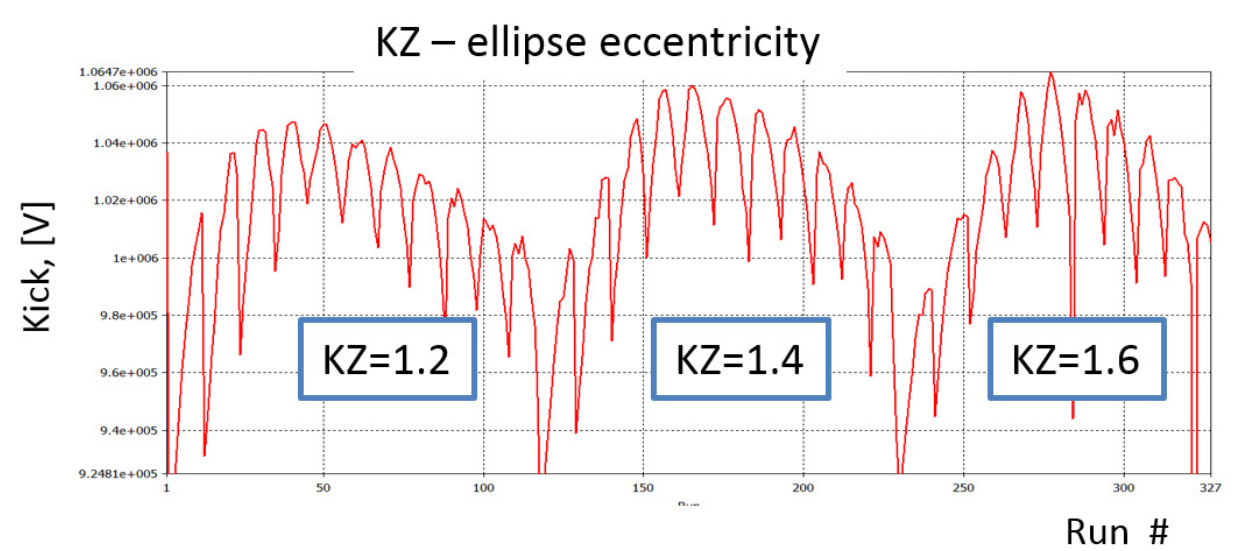

Operating trapped mode surface electric (up) and magnetic (down) fields

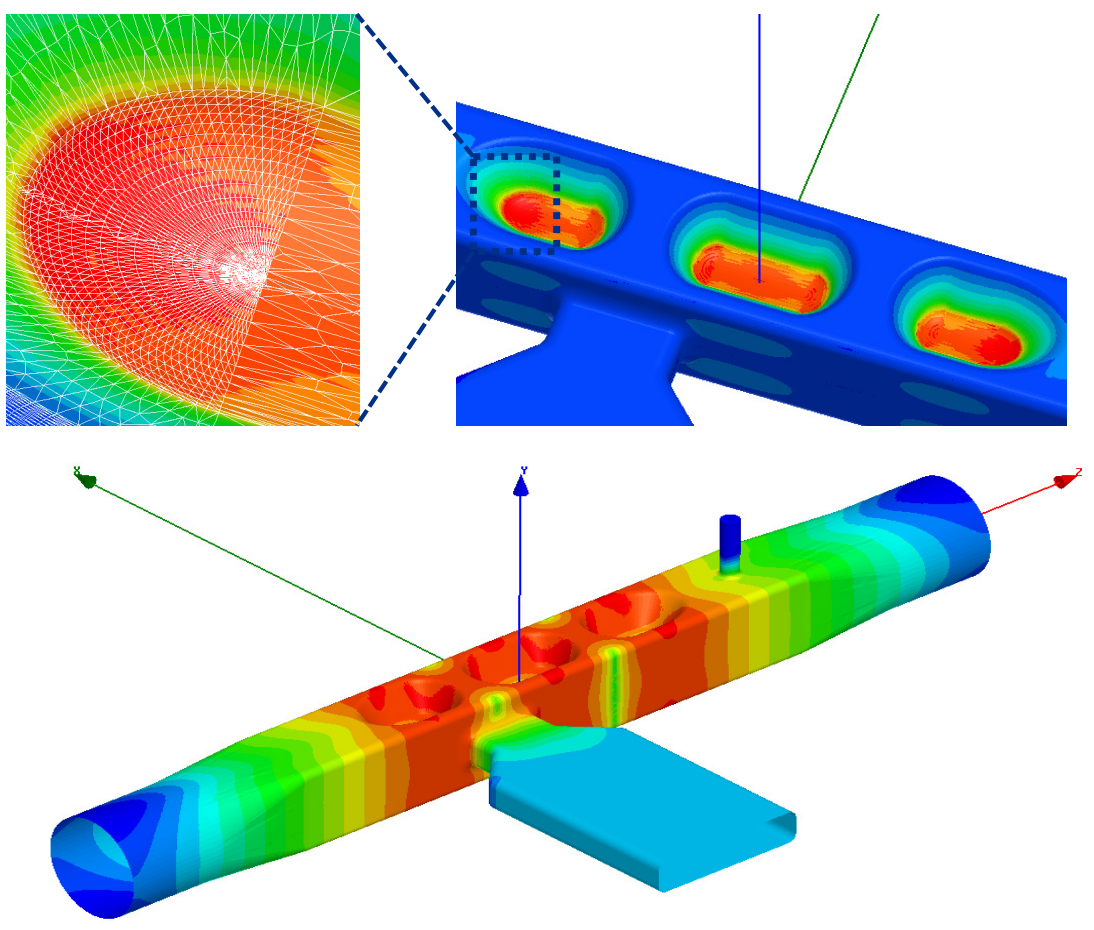

- Model is fully parameterized

- The frequency derivation was calculated for each parameter in order to preserve the operating mode frequency on the stage of geometry creation.

- General ellipsoid is used for hollow surface representation

- Global optimum search algorithm 


\section{Operating Dipole Mode}

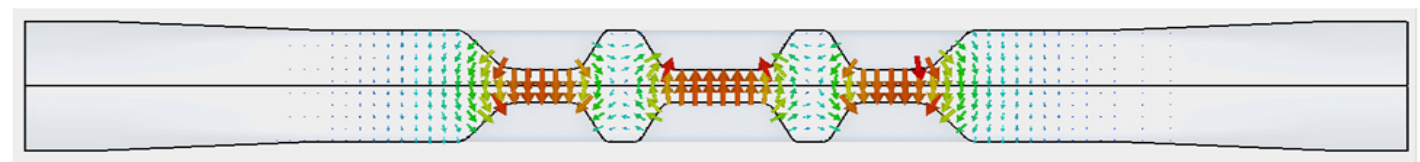

a)

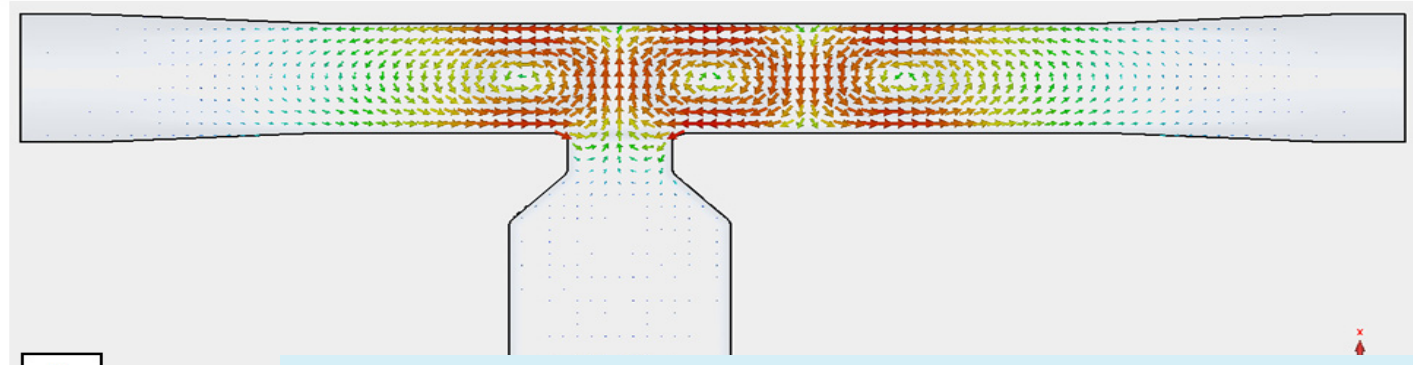

b)

\section{QMiR has a record high $(R / Q)_{t}>1 \mathrm{k} \Omega$}

Integrated vertical kick along the cavity axis (solid red curve is the overall kick, dotted blue and green curves are electric and magnetic kicks).

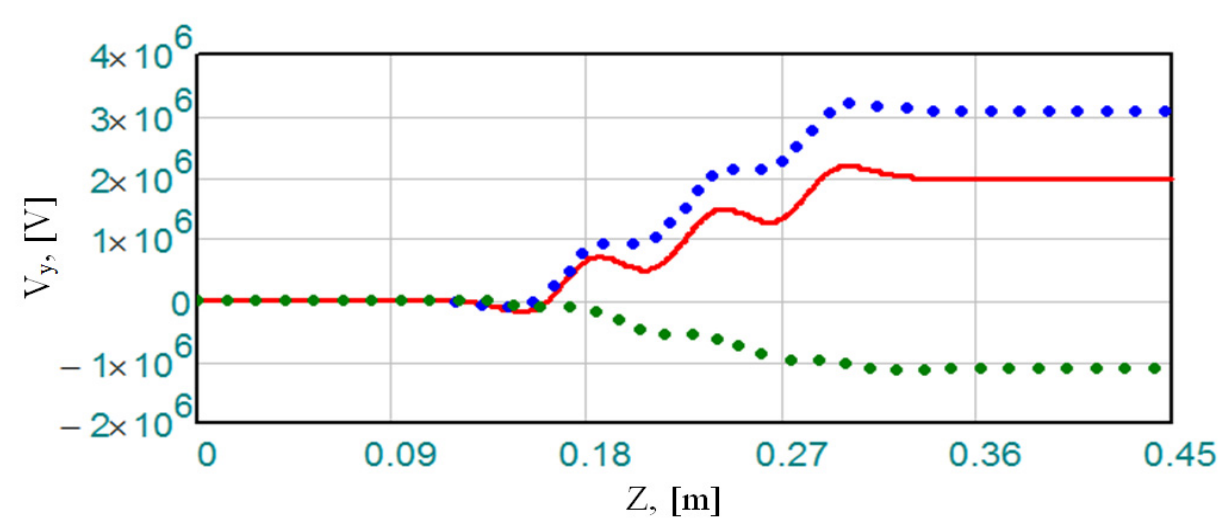

Transverse electric (blue) and magnetic (red) field components along the cavity axis.

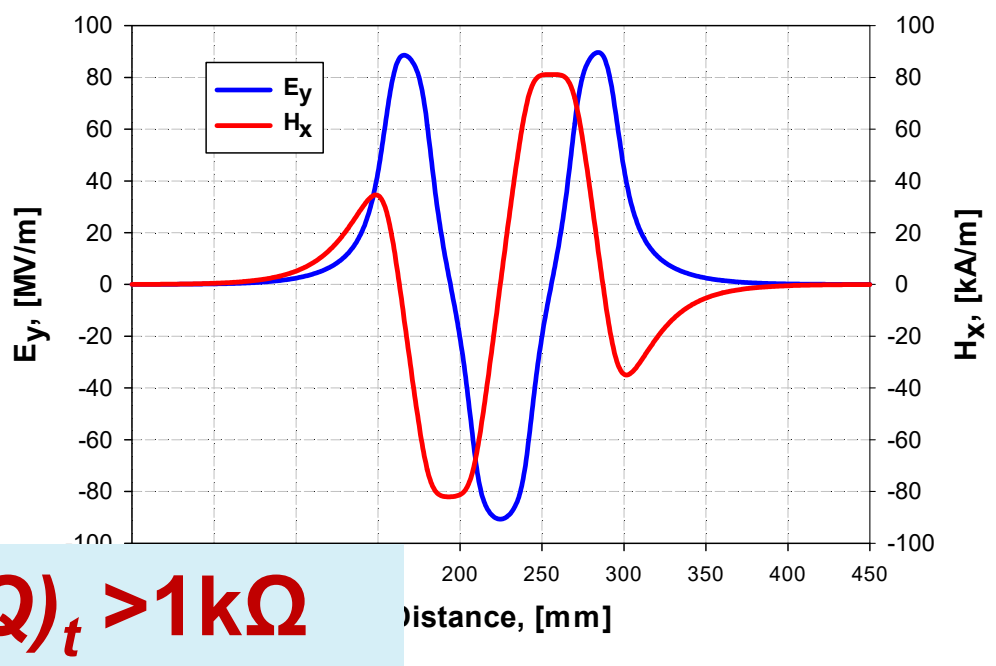

\begin{tabular}{|l|l|}
\hline Freq & $2815 \mathrm{MHz}$ \\
\hline $\mathbf{V}_{\text {kick }}$ & $\mathbf{2} \mathrm{MV}$ \\
\hline $\mathbf{E}_{\max }$ & $\mathbf{5 5 \mathrm { MV } / \mathrm { m }}$ \\
\hline $\mathbf{B}_{\max }$ & $\mathbf{7 6} \mathrm{mT}$ \\
\hline$(\mathbf{R} / \mathbf{Q})_{\mathbf{Y}}$ & $1040 \Omega$ \\
\hline $\mathbf{G}$ & 130 \\
\hline $\mathbf{W}_{\text {STOR }}$ & $0.23 \mathrm{~J}$ \\
\hline
\end{tabular}




\section{Same Order Mode (SOM) Damping}
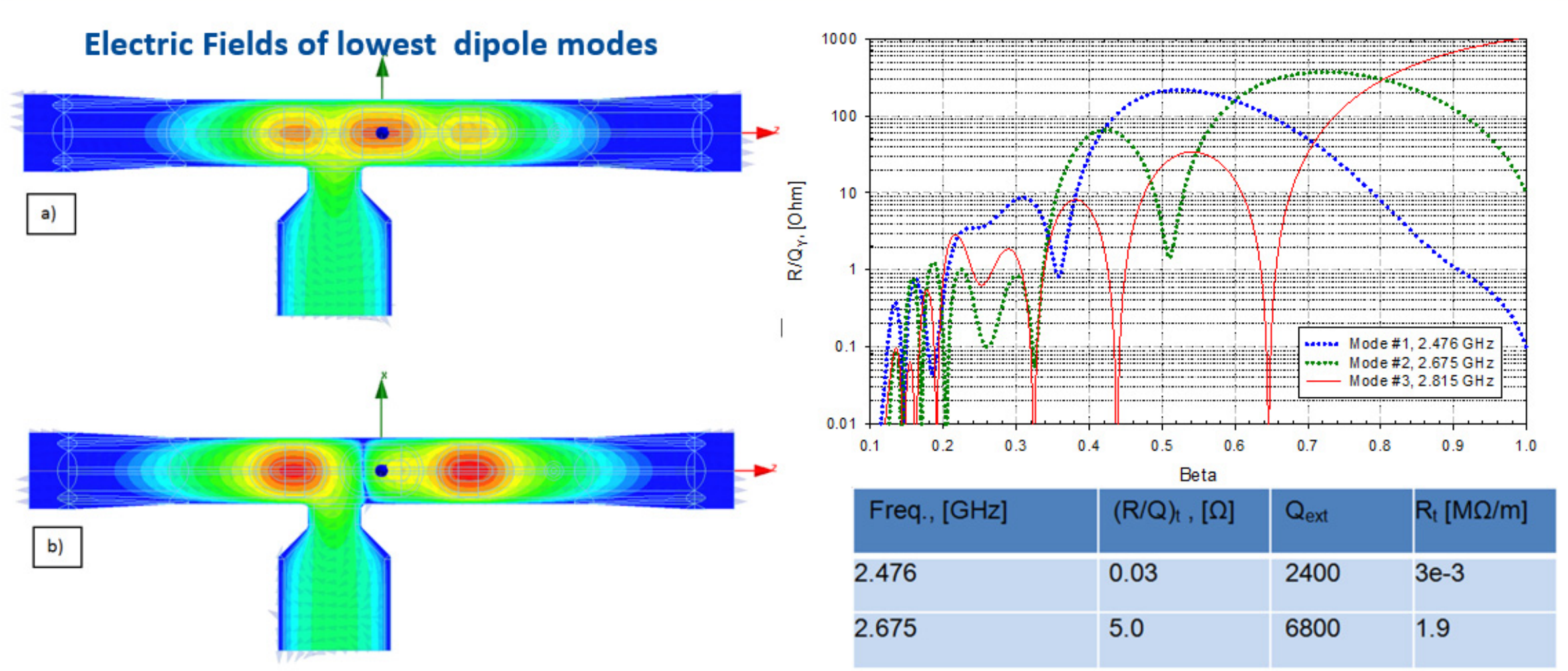

- The fundamental coupler waveguide is used to suppress SOM modes

- The FPC is purposely shifted from the cavity center in order to provide external coupling for the operating mode and damping lower frequency dipole modes simultaneously 


\section{HOM Damping in the APS Ring}

\section{QMiR Cavity Monopole HOMs}

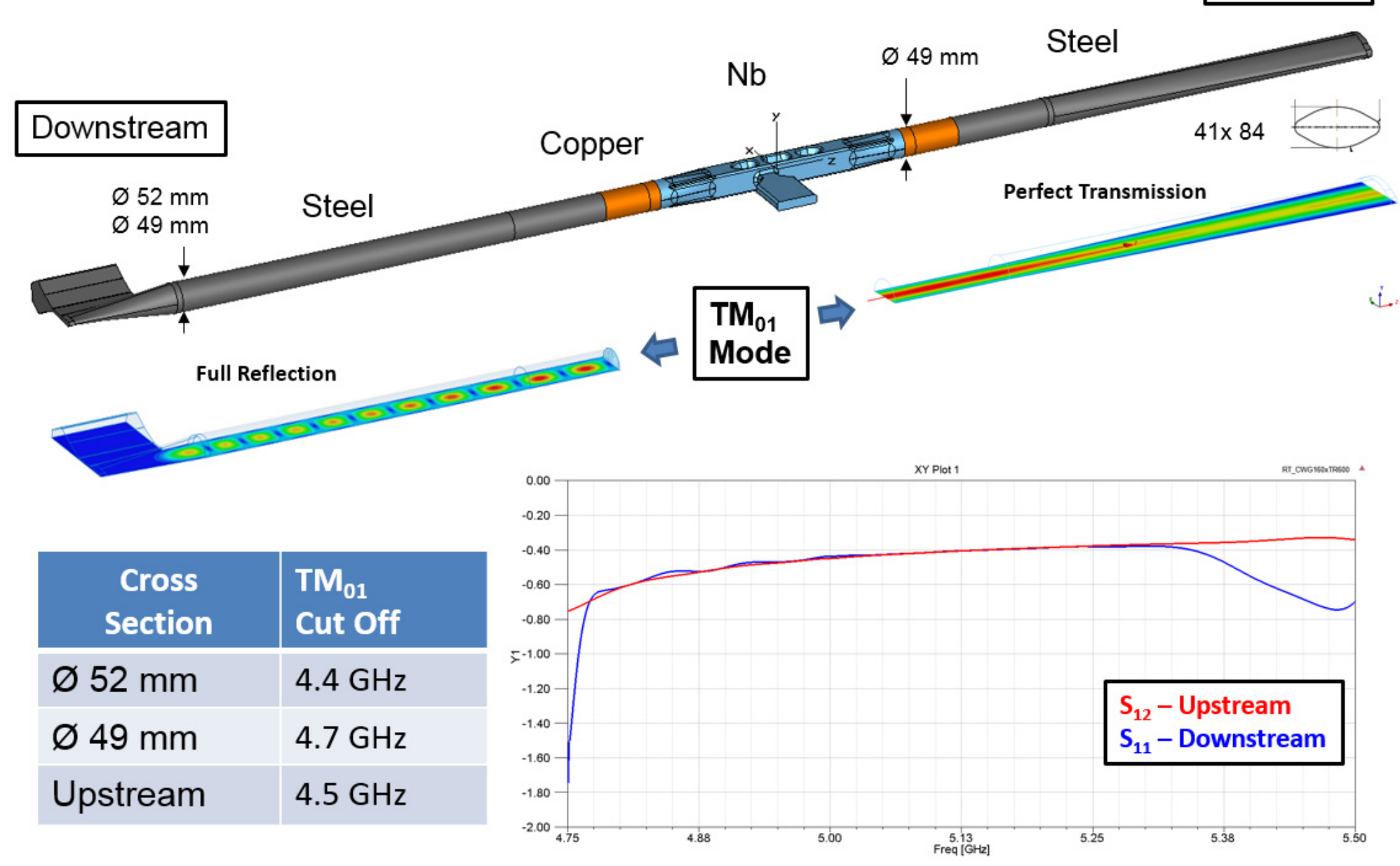

Monopole HOMs RF power is radiated to the Upstream beam pipe ! 


\section{Multipactor Analysis in QMiR}

\section{Multipactor Simulations with CST Studio}
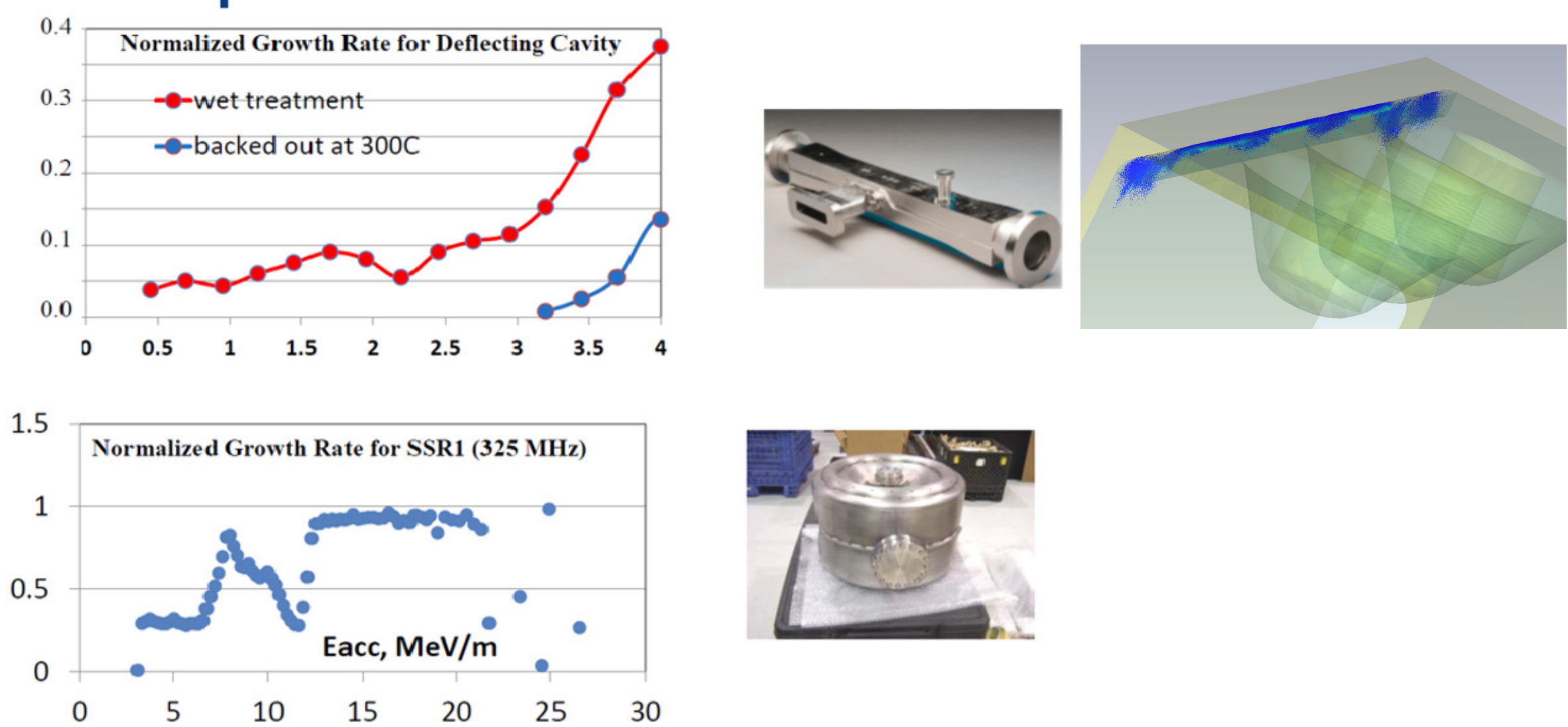

NG Rate in the SSR1 cavity are 10 times higher and MP is successfully processed. QMiR cavity is practically free from MP in the operating RF field domain 


\section{QMIR Prototype Production and Testing}

Bare QMiR (21.75' Long) cavity

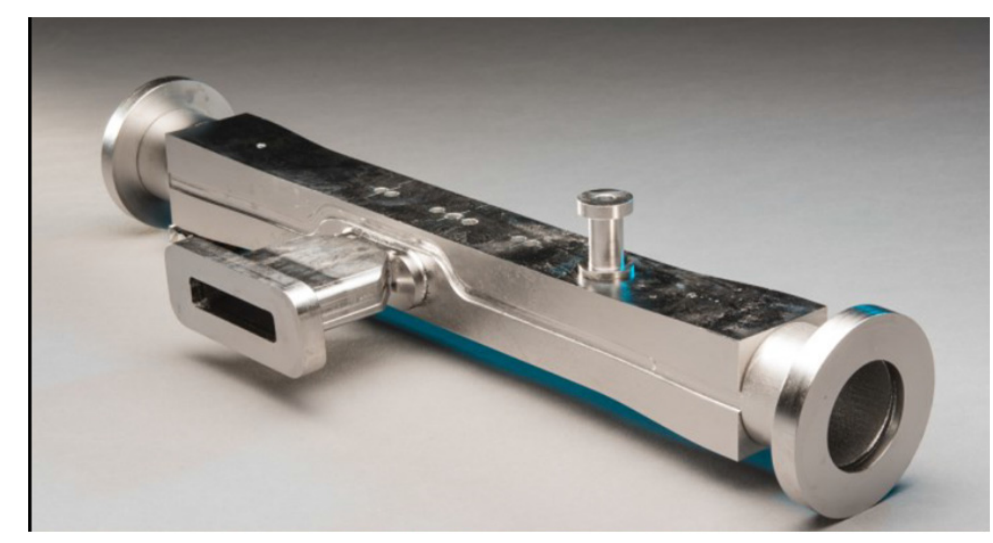

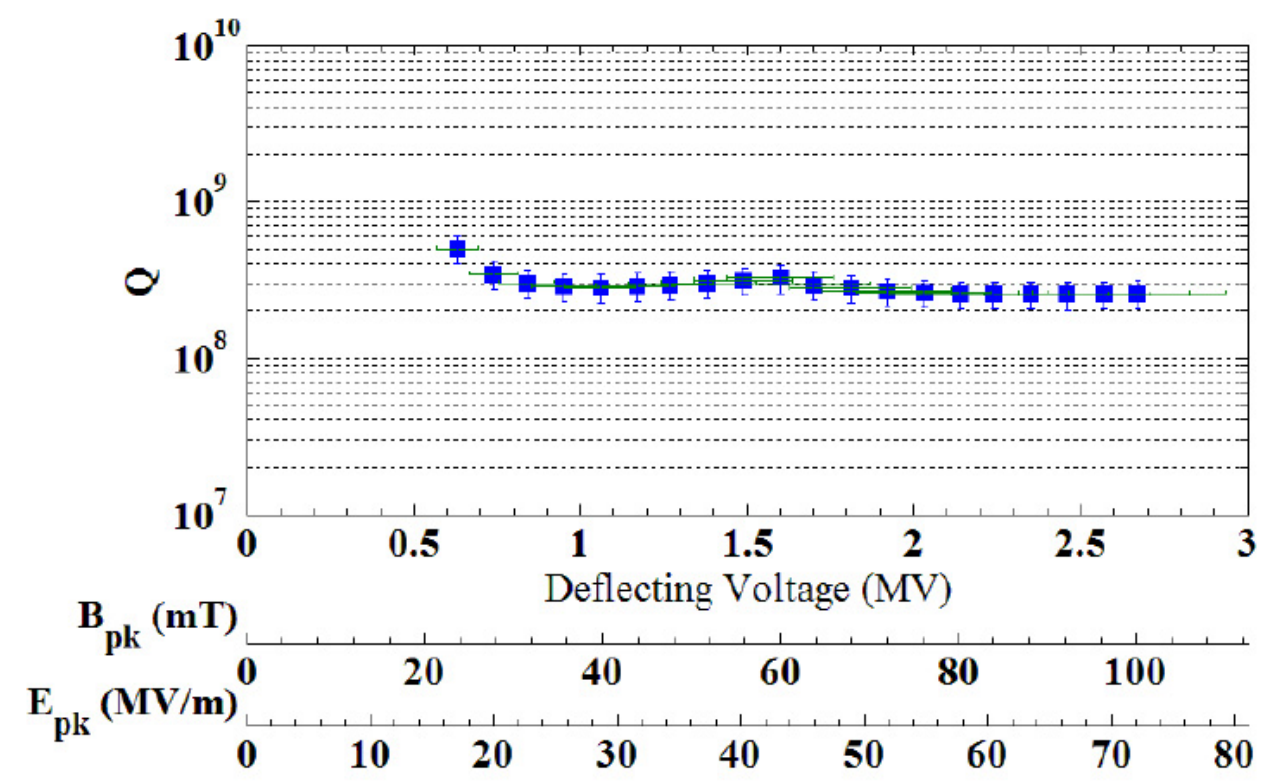

- Cavity received EP-treatment before the test

- Measured maximal deflecting voltage of 2.7 MV exceeded the design goal of 2.0 MV @2K vertical test of QMiR prototype [1]

- Relatively low $Q_{0}(3 E 8)$ is due to extra RF losses at covering flanges

- Further QMiR development was stopped due to the cancelation of ANL/SPX project

Z. Conway, et al., "Development and Test Results of a Quasi-waveguide Multicell Resonator", IPAC14, Dresden, Germany, 2014 苇 Fermilab 


\section{QMIR Application for ILC Crab Cavity}

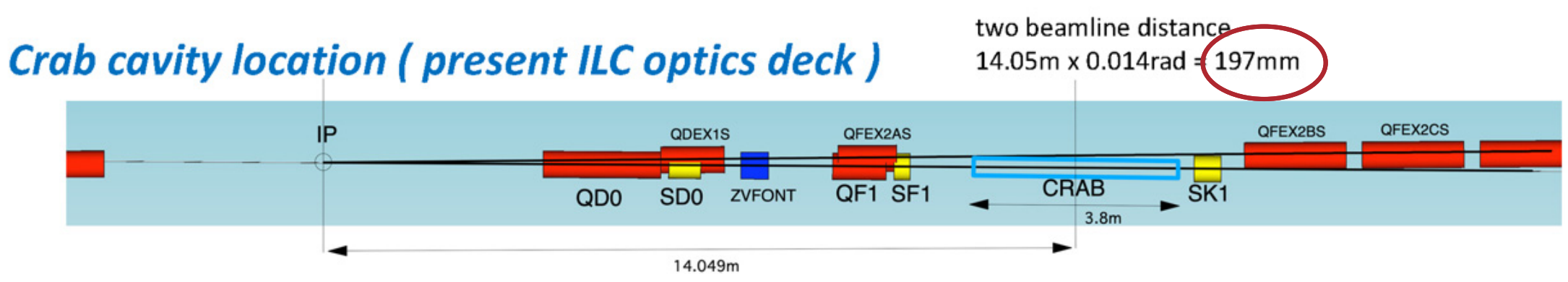

- The kick voltage is inverse proportional to frequency $\left(V_{t} \sim f^{-1}\right)$

- The CC space is limited by a close beamlines distance $(<0.2 \mathrm{~m})$

- For the deflecting voltage of about $0.9 \mathrm{MV}$ the cavity has considerably small surface fields, Ep $\approx 25 \mathrm{MV} / \mathrm{m}, \mathrm{Bp} \approx 35 \mathrm{mT}$

- QMiR cavity @2.6 GHz looks a good choice! 


\section{QMiR Cavity for ILC (scaled to $2.6 \mathrm{GHz}$ )}
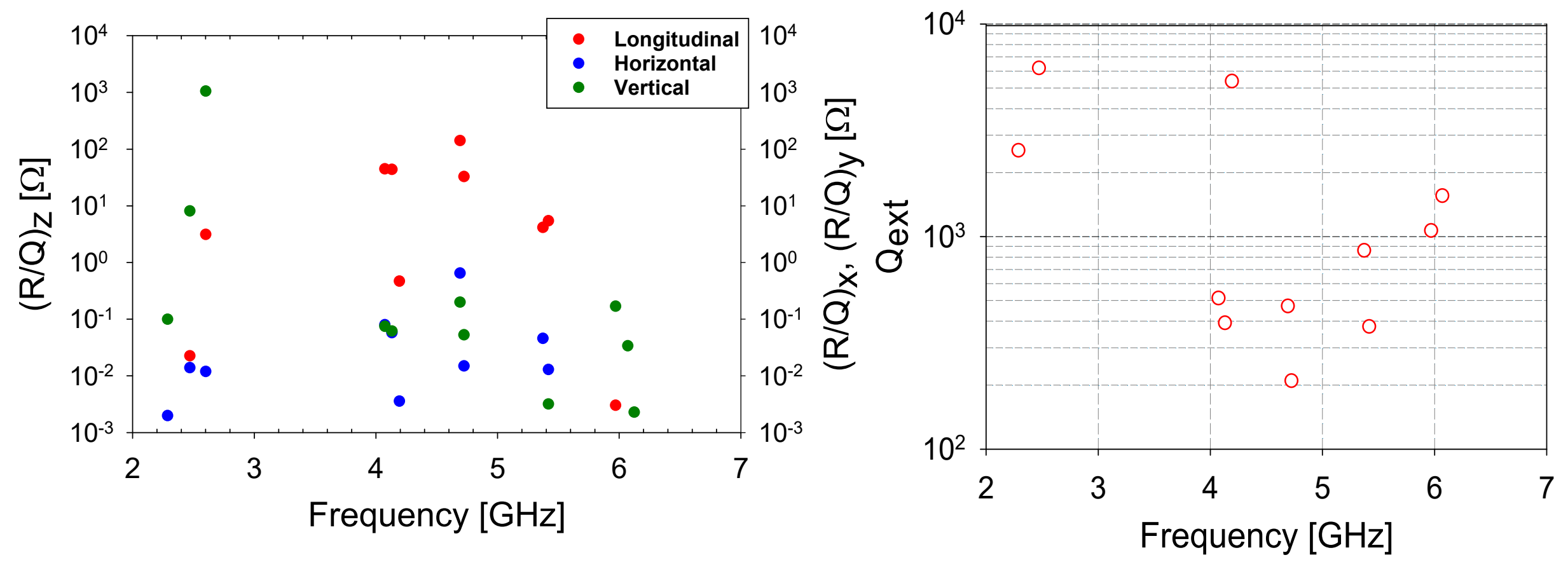

- There are two Same Order Modes (SOM) that have a low $(R / Q){ }^{*} Q$

- SOM/HOM external couplings Qext $<10^{4}$

- SOM/HOMs longitudinal and transverse impedances (@1mm): $(R / Q) z<=100 \Omega,(R / Q) x<=1 \Omega$ and $(R / Q) y<=10 \Omega$

- $\mathrm{SOM} / \mathrm{HOM}$ spectrum is sparse and strongly damped 


\section{Mechanical Analysis LFD and dF/dP (by I. Gonin)}

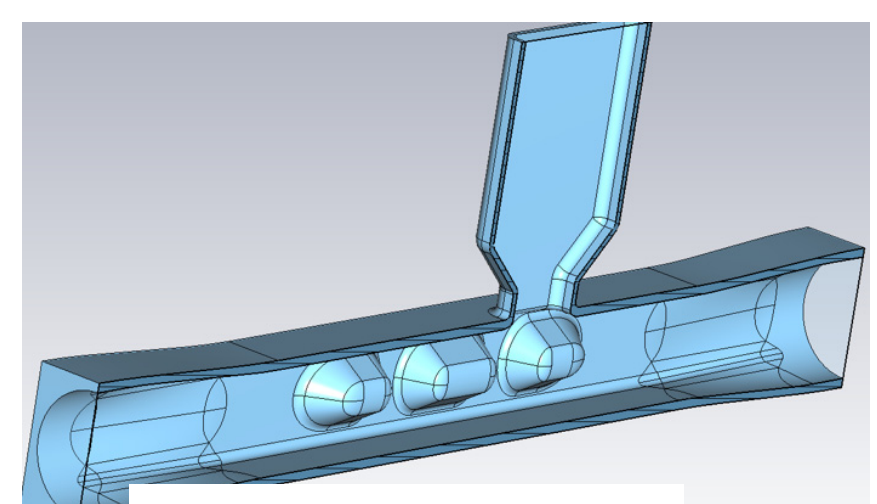

LFD at Kick $=0.9 \mathrm{MeV}$

Wall thickness $4 \mathrm{~mm}$.

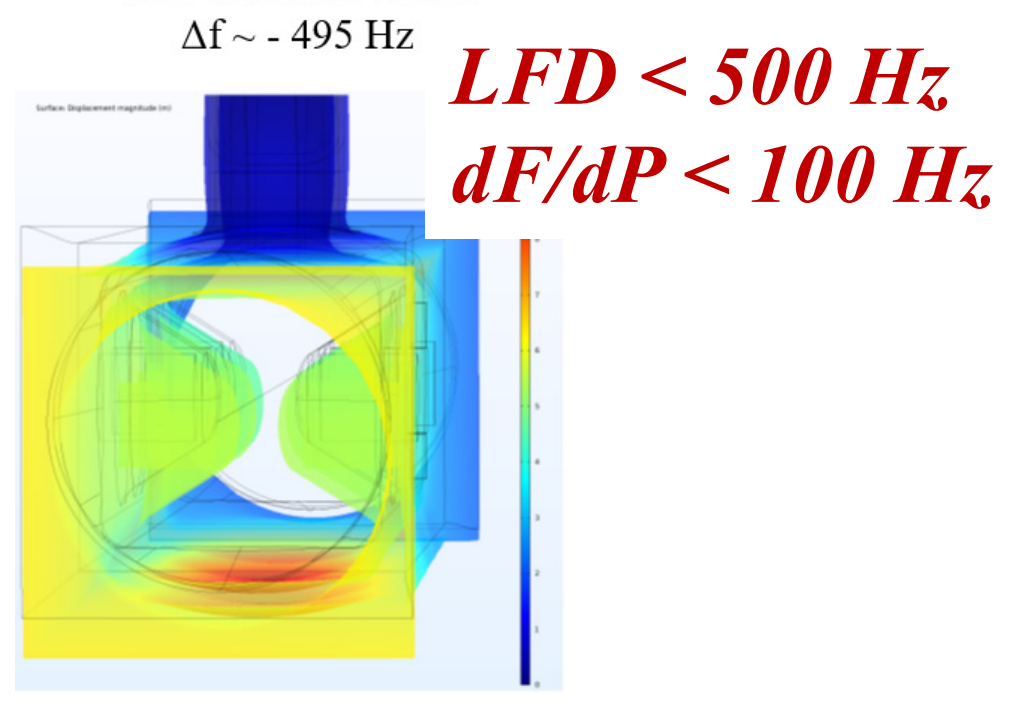

Deformation due to LFD

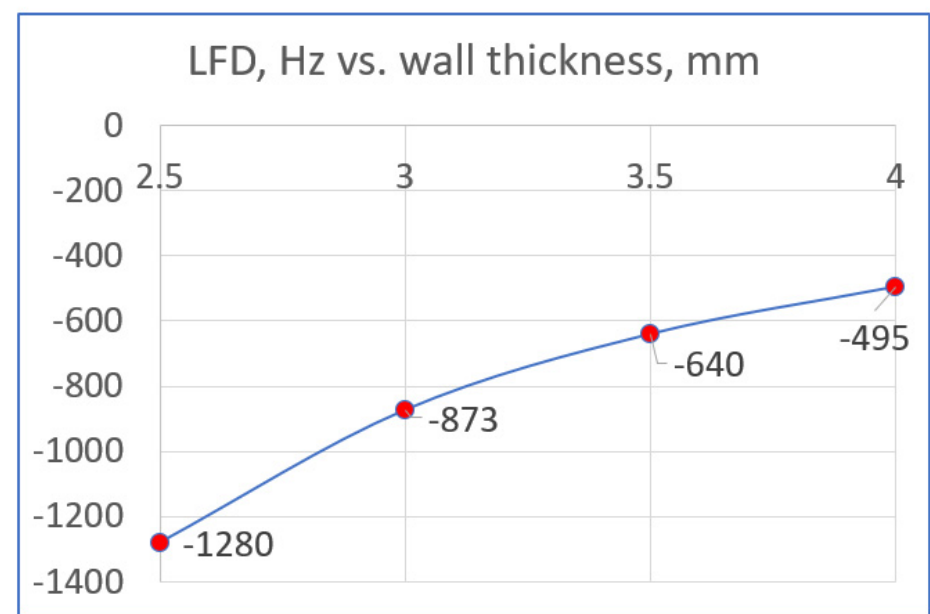

LFD in $\mathrm{Hz}$ at $\mathrm{Kick}=0.9 \mathrm{MeV}$ vs. cavity wall thickness

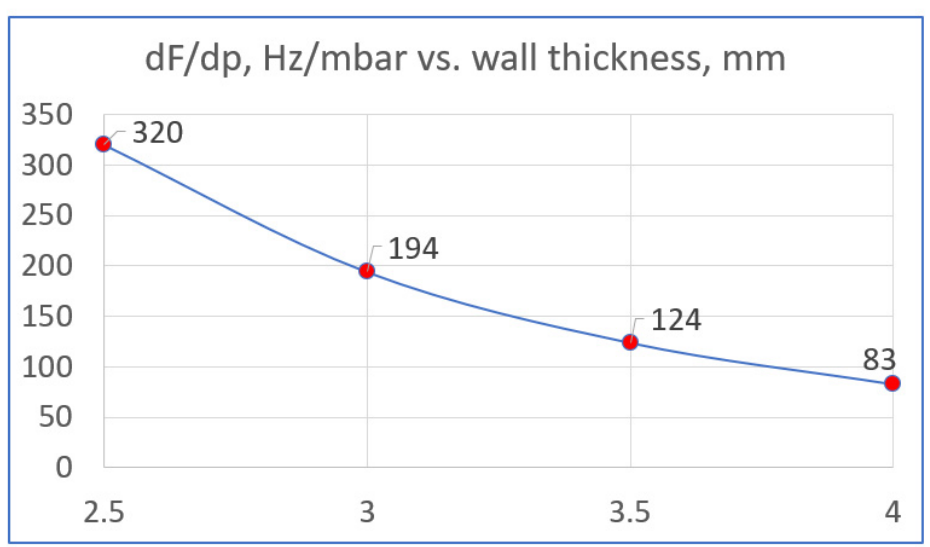

$\mathrm{df} / \mathrm{dP}$ in $\mathrm{Hz} / \mathrm{mbar}$ vs. cavity wall thickness

- QMiR LFD and dF/dP are less than the cavity bandwidth (few $\mathrm{kHz}$ ) 


\section{Mechanical Analysis of Frequency Tuning (by I. Gonin)}

Cavity shell deformations under external force. Wall thickness $4 \mathrm{~mm}$

$\Delta \mathrm{f} / \Delta \mathrm{L} \sim-45 \mathrm{kHz} / \mu \mathrm{m}$

$\Delta \sigma / \Delta$ Force $\sim 17.3 \mathrm{MPa} / \mathrm{kN}$
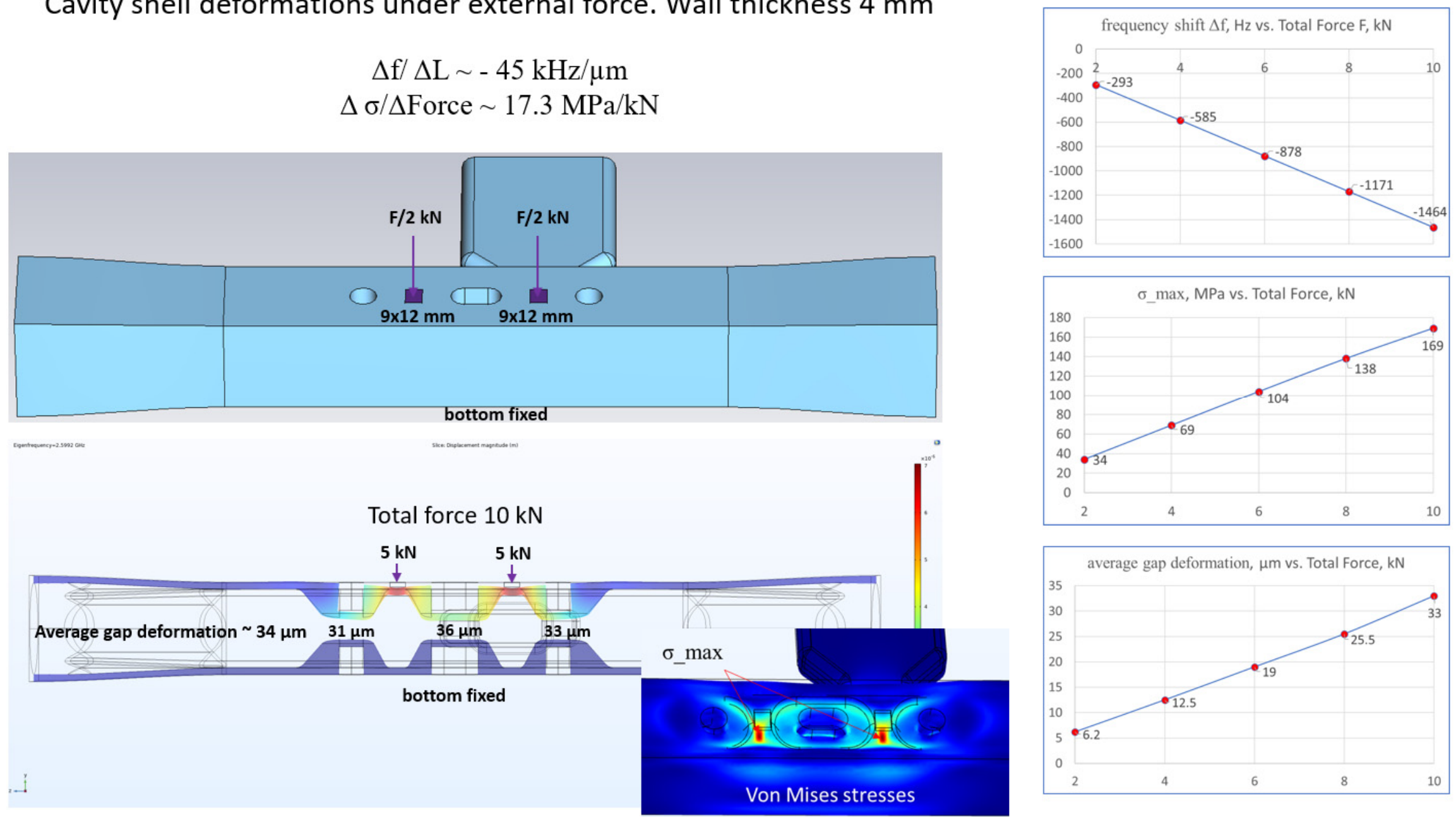

\section{Maximum frequency tuning range: $\sim 1 . .2 \mathrm{MHz}$}




\section{QMiR Cavity Slow Tuner Design (by V. Polubotko)}

Compact lever-type frequency tuner

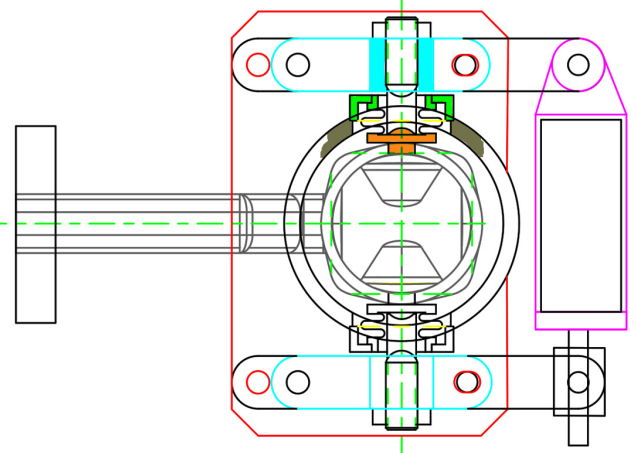

LHe Vessel

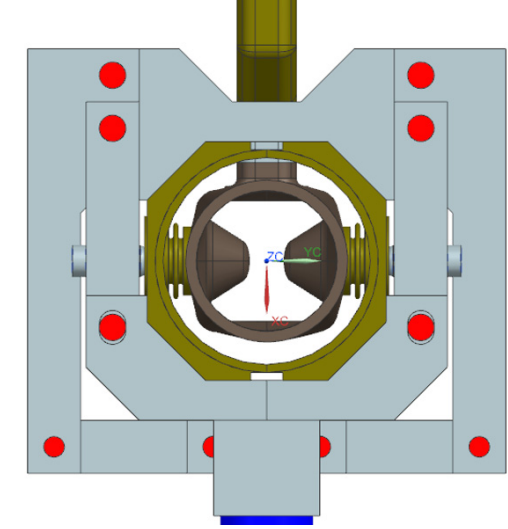

Dressed QMiR Cavity

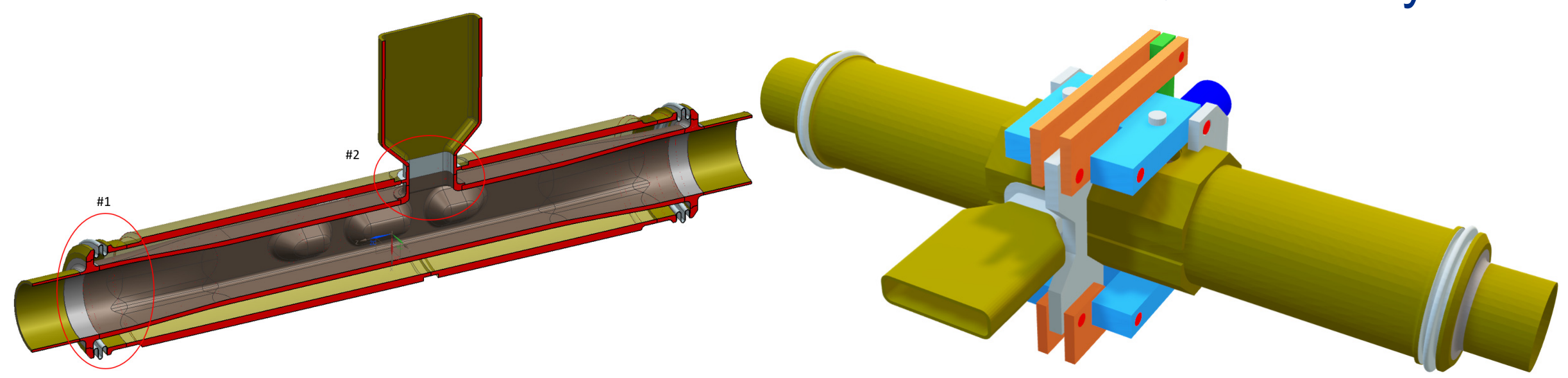

Design of frequency tuner integrated with dressed cavity is ongoing 華 Fermilab 


\section{QMiR Cavity for ELLETRA-II Upgrade (ST Trieste)}

Original scheme for ANL/SPX[1]

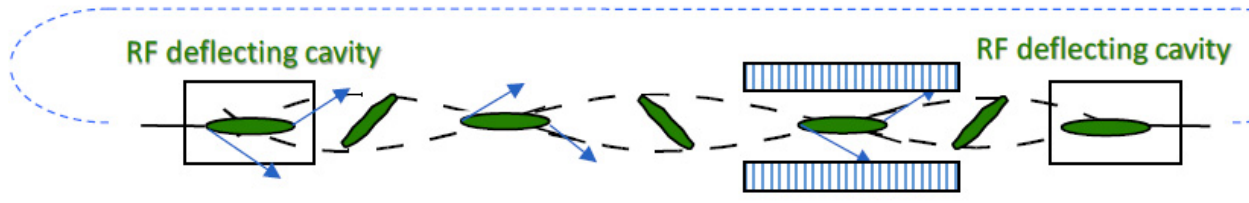

Figure 1-1. Tilt-and-cancel scheme for producing short bunches.

Deflecting System for ST Trieste [2]

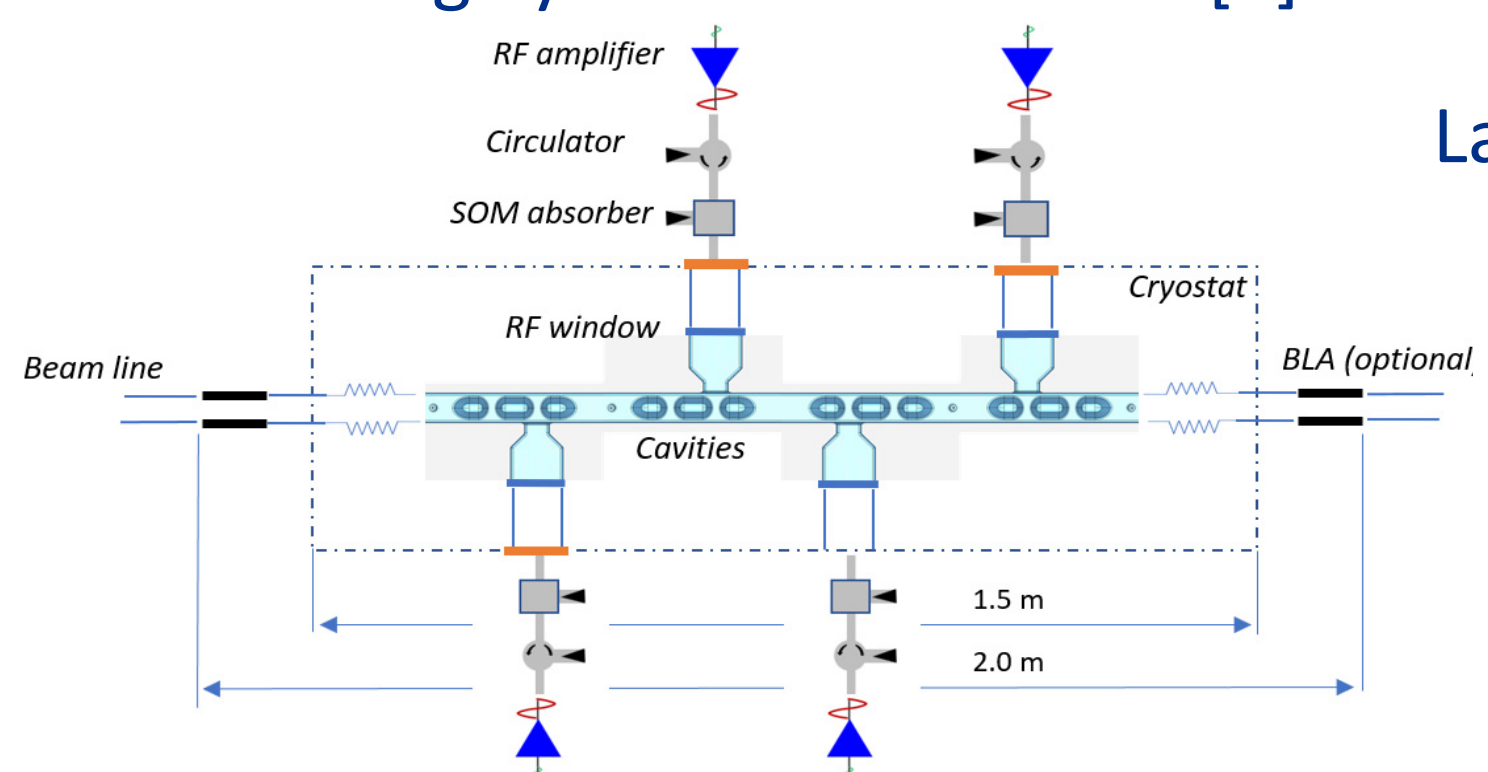

SPX 2-Frequency scheme

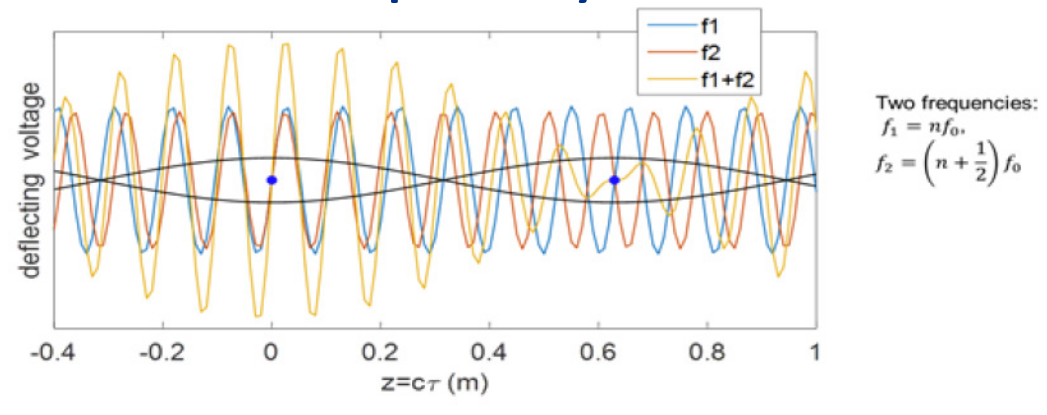

Figure 1-3. Alternating kicked and un-kicked buckets with 2-frequency crab cavities.

Large aperture

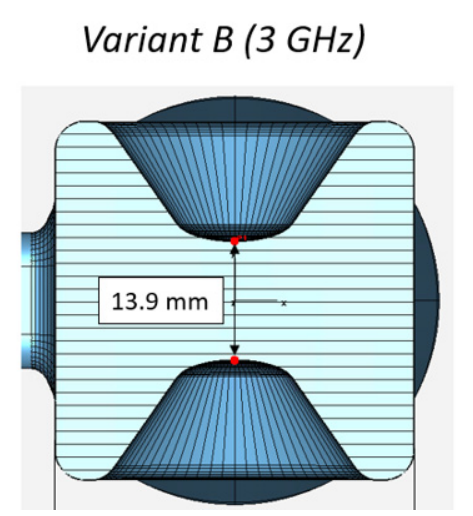

Low B-field

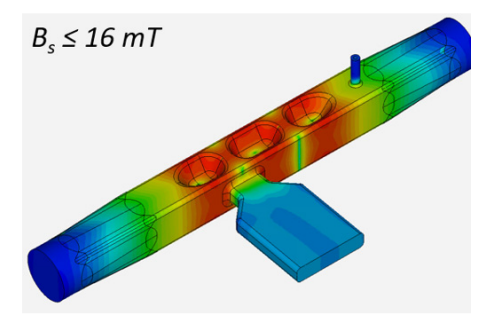

MAC for ST Trieste recommended to proceed with the QMiR type Crab Cavities, $3 \mathrm{GHz}$ and $3.25 \mathrm{GHz}$ for ELLETRA-II upgrade

[1] A. Zholents, P. Heimann, M. Zolotorev, J. Byrd, NIM in Physics Research Section A 425(1-2), 1999.

[2] A. Lunin, T. Khabiboulline, V. Yakovlev, FERMILAB-TM-2756-TD, Technical Note, Fermilab, 2021. 


\section{Conclusions}

A Quasi-Waveguide Multicell Deflecting Resonator (QMIR) is a viable option for Crab and Deflecting Cavities applications

- QMIR is very compact and simple (no HOM-couplers)

- It has sparse HOM spectrum

- It has acceptable loss/kick factors

- No MP in operation voltage domain.

$\square$ QMIR cavity is now being considered for the Elletra-2 and ILC projects.

- It meets all the project requirements

$\square$ Fermilab can design, build and test QMIR cavities for a variety of particle accelerator applications 


\section{Backup Slides}




\subsection{GHz QMiR for ILC Crab Cavity}

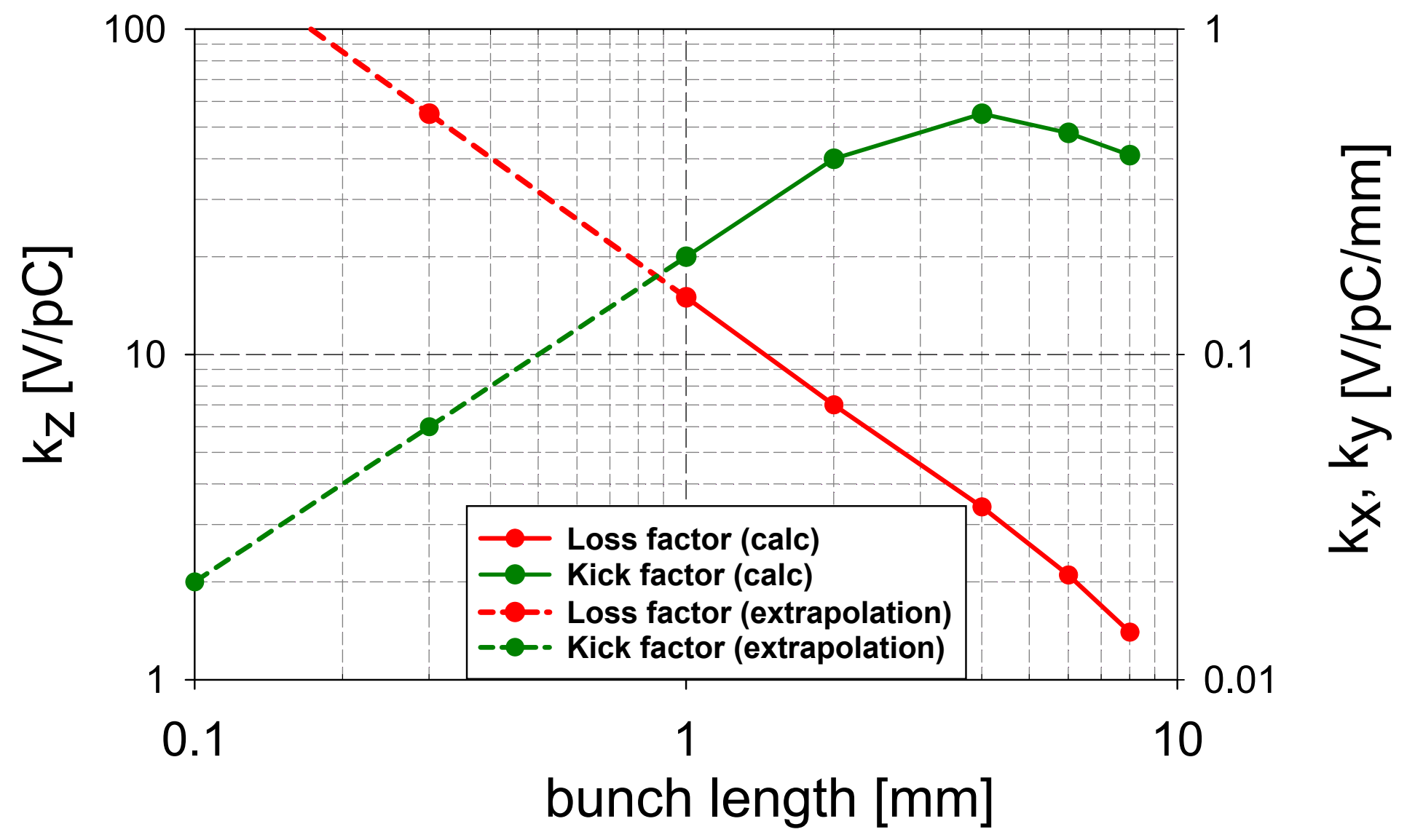

For the ILC bunch length $(0.3 \mathrm{~mm}$ rms), the loss and kick factors:

$\mathrm{k} \_$loss $<=50 \mathrm{~V} / \mathrm{pC}$ and $\mathrm{k}$ _kick $<=0.1 \mathrm{~V} / \mathrm{pC} / \mathrm{mm}$ 


\section{High Order Mode (HOM) Damping}

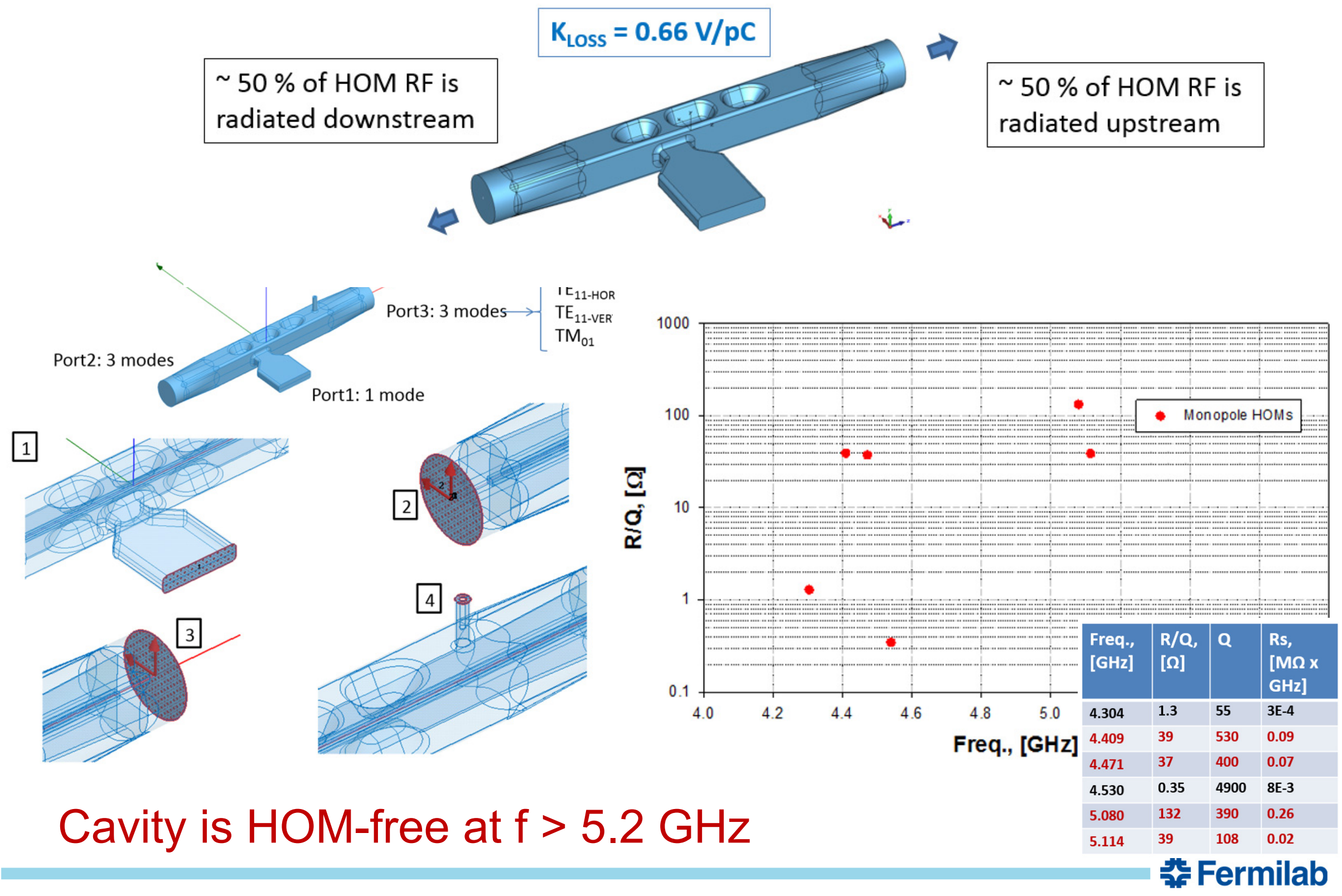

21 10/27/21 A. Lunin | Alternate Crab Cavity Design 


\section{QMiR Cavity for ILC (scaled to $2.6 \mathrm{GHz}$ )}

Operation mode

$$
\left(\frac{r_{\perp}}{Q}\right)=1040 \text { Ohm }(@ 2.6 \mathrm{GHz})
$$

Maximal dipole horizontal HOM $\left(\frac{r_{\perp}}{Q}\right)_{x}<10 \mathrm{Ohm}(@ 2.5 \mathrm{GHz})$;

$$
\mathrm{Q}<1 \times 10^{5}\left(<\mathrm{Q}_{\max } \approx 2.4 \times 10^{6}\right)
$$

Maximal dipole vertical HOM

$$
\begin{aligned}
& \left(\frac{r_{\perp}}{Q}\right)_{y}<10 \mathrm{Ohm}(@ 4 \mathrm{GHz}) ; \\
& \mathrm{Q}<1 \times 10^{4}\left(<\mathrm{Q}_{\max } \approx 1.7 \times 10^{6}\right)
\end{aligned}
$$

Horizontal kick factor*

$$
\begin{aligned}
& k_{x}=100(<2300) \mathrm{V} / \mathrm{pC} / \mathrm{m} \\
& k_{y}=400(<2500) \mathrm{V} / \mathrm{pC} / \mathrm{m}
\end{aligned}
$$

Vertical kick factor*

* GdfidL calculation for $0.3 \mathrm{~mm}$ bunch length (cross check with ECHO-3D code is ingoing)

- QMiR cavity meets the ILC/CC horizontal and vertical HOM impedance requirements 


\section{QMiR Cavity for ILC RF Power}

- RF power needed to maintain the crabbing voltage should compensate

- the ohmic losses in the cavity (negligible for SRF cavities)

- voltage induced by the beam if the is off the cavity axis

- The maximal required RF power for the detuned cavity:

$$
P=\frac{U_{0}^{2}}{4 Q\left(\frac{r_{\perp}}{Q}\right)}\left[\left(1+\frac{I_{p} Q\left(\frac{r_{\perp}}{Q}\right) k_{0} x_{0}}{U_{0}}\right)^{2}+\left(\frac{2 Q \Delta \omega}{\omega_{0}}\right)^{2}\right]
$$

- For max beam offset $\mathrm{x}_{0}<1 \mathrm{~mm}$ and $\Delta f<1 \mathrm{kHz}$ (LFD, microphonics)

Beam OFF:

Optimal Coupling:

Beam ON \& Microphonics:

$$
\begin{aligned}
& P_{\text {min }} \approx 200 \mathrm{~W} \\
& \mathrm{Q}_{L} \approx 1 \times 10^{6} \\
& P_{\text {max }} \approx 500 \mathrm{~W}
\end{aligned}
$$

- Required RF power from the generator (overhead 100\%):

$$
P_{\text {gen }}<1 \mathrm{~kW}
$$

